\title{
O sabor da história: práticas alimentares e identidade quilombola. ${ }^{1}$
}

\begin{abstract}
Alexandra Santos ${ }^{2}$
\section{Resumo}

Com este artigo, suscitamos algumas considerações a respeito dos estudos das práticas alimentares de remanescentes quilombolas como via de acesso à compreensão do processo de construção da identidade étnica dessas comunidades. Balizados pelos pressupostos da socionatropologia da alimentação, construímos uma análise da relação que quilombolas estabelecem com o alimento, com a comida e com alguns utensílios domésticos. Tomada como fato social, a alimentação nos conduz ao entendimento de dois aspectos sobre a construção identitária dos quilombolas: o primeiro diz respeito à forma como esses atores se percebem e se localizam socialmente e como, a partir de suas escolhas alimentares, se relacionam com sua história. O segundo aspecto está relacionado ao acionamento da identidade étnica que é realizado na medida em que, em um processo de alteridade, as decisões quanto ao que comer e com quem comer revelam como os quilombolas se aproximam e se afastam do outro, construindo sua subjetividade.
\end{abstract}

Palavras-chave: quilombolas, alimentação, identidade.

\begin{abstract}
This article aims at considering some aspects about quilombolas' eating habits as a path through which the ethnic identity construction should be understood. Based on socioanthropology of food assumptions we present an analysis of how quilombolas deal with food, and some domestic utensils. Explored as a social fact, nourishing leads us to understand how quilombolas see themselves as a social group, and how they keep in contact with their past. Eating habits and choices are also seen as a way these actors construct their subjectivity. define who they are, and mainly the others are.
\end{abstract}

Keywords: quilombolas, eating habits, identity.

\footnotetext{
1 Artigo elaborado a partir das discussões realizadas na dissertação de mestrado, intitulada: Entre a colher e a enxada: interfaces entre a alimentação e a cultura dos quilombolas de Piranga- MG, apresentada ao programa de Pós-Graduação em Extensão Rural, pela Universidade Federal de Viçosa, aprovada no dia 25 de junho de 2009.

${ }^{2}$ Doutoranda do departamento de Ciências Sociais da Universidade do Estado do Rio de Janeiro. Bolsista da Fundação de Amparo à Pesquisa do Rio de Janeiro
}

INTRATEXTOS, Rio de Janeiro, Número Especial 03, pp.54-71, 2012. 


\section{INTRODUÇÃO}

Os estudos sobre os processos de construção e acionamento de uma identidade étnica por parte das chamadas comunidades de remanescentes quilombolas ocupa, em um movimento crescente, pastas de abordagens prementes na antropologia. Neste artigo, nos propomos a pensar em como os quilombolas constroem um matiz dessa identidade étnica, a partir das escolhas que fazem à mesa.

Nossa proposta vai ao encontro dos pressupostos da socioantropologia da alimentação e, desta forma, pensa em uma análise que não se basta no ato de "colocar a cozinha e as maneiras à mesa como representação e teatralização dos valores de uma cultura e, consequentemente, como lugar de leitura das identidades culturais” (POULAIN, 2006, p. 153), mas sim, assume como necessária a tradução dessas representações, a construção de uma estrutura lógica para uma prática que é imperceptível àquele nela inserido. No que se refere à construção da identidade étnica de quilombolas, a tradução das representações dos valores de sua cultura é realizada a partir do mapeamento de signos do cotidiano; em nosso caso, signos que emergem das escolhas, práticas e hábitos alimentares de quilombolas de três comunidades de localizadas no município de Piranga, na Zona da Mata mineira: Santo Antônio de Pinheiros Altos, Bordões e Castro.

O artigo é organizado em três partes, sistematizadas da seguinte forma: na primeira, discorremos sobre a relevância da alimentação como um dado cultural, objeto de estudo das ciências sociais. Na segunda parte do ensaio, apresentamos uma visão panorâmica sobre o processo de inserção dos quilombolas, enquanto categoria, social no cenário brasileiro; o que culminou em uma série de mudanças na estrutura social e, consequentemente, em um movimento de (re)construção de uma identidade étnica desses grupos.

Ao final do trabalho, trazemos uma análise da relação que quilombolas estabelecem com o alimento, com a comida e com alguns utensílios domésticos da cozinha, a fim de compreender como, a partir dessas relações, esses atores se constroem enquanto sujeitos, delimitam os espaços entre eu e o outro e acionam essa identidade étnica (re) construída. 


\title{
O SABOR DA CULTURA: alimentação como objeto de estudo das ciências sociais
}

A comida, as práticas e os hábitos alimentares, há muito tempo, ocupam espaço multidisciplinar no cenário investigativo. Como fonte básica para a manutenção e reprodução do ser humano, os alimentos são objeto fundamental nos estudos das ciências médicas, biológicas e agrárias. Às ciências sociais, a comida interessa a partir do momento em que é tomada como fato social, dotado de poder simbólico, pelo qual perpassam dados culturais e identitários. Nesse sentido, o foco de interesse de cientistas sociais são as relações de comensalidade, ou seja, as formas pelas quais o homem interage e se organiza socialmente em torno da comida. Sobre a relação entre o alimento e o homem, Fischler(2001) assume:

\begin{abstract}
Comer: nada de mais vital, nada de tão íntimo. "Íntimo" é o adjetivo que se impõe: em latim, intimus é o superlativo de interior. Incorporando os alimentos, nós os fazemos acender ao auge da interioridade. [...] O vestuário, os cosméticos, estão apenas em contato com o nosso corpo; os alimentos devem ultrapassar a barreira oral, se introduzir em nós e tornar-se nossa substância íntima. Há então, por essência, alguma gravidade ligada ao ato de incorporação: a alimentação é o domínio do apetite e do desejo gratificados, do prazer, mas também da desconfiança, da incertude e da ansiedade. (FISCHLER, 2001, p. 7)
\end{abstract}

O homem é aquilo que come! Esta máxima, frequentemente usada nos manifestos de vegetarianos, dos adeptos do slow food e de grupos que, em geral, primam por uma alimentação saudável, sinaliza a relação entre prática alimentar e construção do homem enquanto sujeito integrado a espaços e sistemas sociais culturalmente determinados. A este respeito, Millán afirma que:

\footnotetext{
$\mathrm{Na}$ alimentação humana se materializa a estrutura da sociedade, se atualiza a interação social e socioambiental, as representações socioculturais (crenças, normas, valores) que dão significado à ação social [...] dos que têm em comum uma mesma cultura. A abstração conceitual da cultura se concretiza no prato (MILLÁN, 2002, p. 277 278).
}

As palavras do autor reforçam a proposição de que a comida opera como elemento de pertença. As escolhas e os rituais relativos à alimentação são socialmente estabelecidos e se 
relacionam diretamente à posição que determinadas sociedades ou grupos sociais ocupam. Desta forma, compreende-se que os hábitos alimentares estão vinculados à memória, ao imaginário. A esse respeito, Fischler (1979) observa que:

\begin{abstract}
O homem é um onívoro que se alimenta de carne, de vegetais e de imaginário: a alimentação conduz à biologia, mas, é evidente, não se reduz a ela; o simbólico e o onírico, os signos, os mitos, os fantasmas também alimentam e concorrem a regrar nossa alimentação (FISCHLER, 1979, p. 01)
\end{abstract}

Seguindo a perspectiva dos autores acima citados, é possível assumir que os hábitos alimentares fornecem dados sobre relações sociais e, consequentemente, sobre as disputas de poder, ocupação de espaços sinalizadores de status, caracterização de gênero, etnia, faixa etária, ou seja, sobre a identidade. Como um dado, a alimentação se inscreve no quadro de atos sociais cujo poder simbólico permite a compreensão da formatação da cultura de uma sociedade, ou de um grupo social. As escolhas alimentares, entretanto, não ocorrem em um movimento estanque de outros fatos do cotidiano. Há uma relação dialógica entre aquele que come e a comida.

Mapear o quadro das escolhas e dos rituais que envolvem os hábitos à mesa significa, em certa medida, sistematizar parte da história e da composição social de um grupo. Há, por trás dos rituais da alimentação, um universo simbólico que ultrapassa as margens dos pratos e das panelas. A transformação não ocorre somente de dentro para fora. A comida começa a alimentar a partir dos roçados, dos mercados, dos pastos; e não dos talheres. O percurso do alimento é crivado de representações sociais.

A comida, segundo Mintz (2001), une universos distintos; ela é uma base que:

\begin{abstract}
liga o mundo das coisas ao mundo das idéias por meio de nossos atos [...] ela "entra" em cada ser humano. A intuição de que é de alguma maneira substanciado - e encarnado - a partir da comida que se ingere pode, portanto, carregar uma espécie de carga moral. Nossos corpos podem ser considerados o resultado, o produto de nosso caráter, que por sua vez, é revelado pela maneira que comemos (MINTZ, 2001, p. $32)$.
\end{abstract}

É a partir dessa perspectiva que os cientistas sociais estudam a comida. Sua importância, mais que nutritiva, é social e será a partir dela que pensaremos nas práticas alimentares dos quilombolas de Piranga/MG. Os alimentos têm nacionalidade, têm status, têm 
poder, tal qual aquele que os prepara e/ou que os ingere.

As transformações sociais e políticas de um grupo ocorrem também em níveis de consumo. A difusão de alguns alimentos está condicionada à expansão de seus países e regiões de origem. Como afirma Mintz:

\begin{abstract}
a introdução do cultivo da batata pela Europa central, da Irlanda à Sibéria; o rápido sucesso da pimenta do reino em Szechwam, África Ocidental e Índia; a popularização de chá, café, açúcar e chocolate pela Europa [...] são algumas lembranças da transformação revolucionária dos hábitos alimentares, para o leste e para o oeste (MINTZ, 2001, p. 33).
\end{abstract}

Quando se objetiva elucidar questões relativas ao porquê e ao como esses alimentos saíram de seus países de origem e passaram a integrar outras cozinhas, chega-se a respostas possíveis de mapear o percurso sociopolítico dos povos a eles relacionados. Neste sentido, Brillat-Savarin (1995, p. 58) afirma que:

\begin{abstract}
Os hábitos alimentares de uma nação não decorrem somente do mero instinto de sobrevivência e da necessidade do homem se alimentar. São expressão de sua história, geografia, clima, organização social e crenças religiosas [...]. O gosto, que muitos acreditam ser próprio, é uma constelação de extrema complexidade, na qual entram em jogo, além da identidade idiossincrática, fatores como: sexo, idade nacionalidade, religião, grau de instrução, nível de renda, classe e origem sociais. O gosto é, portanto, moldado culturalmente, e socialmente controlado. (SAVARIN,1995, p. 58)
\end{abstract}

A partir dessa dinâmica de aceitação, consumo, reconhecimento e identificação alimentar, ocorre a transformação do alimento em comida, ou seja, aquele passa a ser inscrito no quadro dos matizes culturais de uma sociedade ou grupo social. No que tange à questão da construção da identidade étnica dos quilombolas de Piranga-MG, pensamos em como ela se configura, tendo como base de nossa reflexão os elementos múltiplos que envolvem esse processo social de transformação do alimento em comida.

Nosso trabalho de observação e participação de momentos distintos dos rituais alimentares das comunidades de remanescentes quilombolas mostrou que os hábitos alimentares do presente simbolizam não somente aquilo que, hoje, esses sujeitos podem comer, por não mais estarem sob a condenação do cativeiro e do chicote. A relação que têm com o alimento e com a possibilidade do acesso ao mesmo, mais que sinalizar as 
transformações políticas e sociais pelas quais esses atores passaram após a abolição, ela os integra como sujeitos no cenário social nacional. Mas, em que contexto se insere esta história?

\section{HISTÓRICO SABOR: QUILOMBOLAS NO CONTEXTO NACIONAL}

Pensar na categoria "remanescentes quilombolas" no Brasil, atualmente, requer um esforço reflexivo no sentido de compreender como esses grupos foram integrados ao cenário social brasileiro e como eventos políticos intervieram na dinâmica que hoje encontramos nessas comunidades.

É sabido que a questão da identidade étnica das comunidades de remanescentes quilombolas, sobretudo no que tange ao processo de autoatribuição (ou autorreconhecimento), ganha emergência nas pautas de discussões sociais, políticas e acadêmicas nacionais por meio dos pressupostos dos artigos 215 e 216, da Constituição Federal de 1988. Esses artigos são complementados, no que diz respeito especificamente aos quilombolas, pelo emblemático artigo 68 do Ato das Disposições Constitucionais Transitórias (ADCT), a partir do qual às comunidades remanescentes quilombolas, que estejam ocupando suas terras, é reconhecida a propriedade definitiva, devendo o Estado emitir-lhe títulos respectivos.

$\mathrm{O}$ fato de conceder o direito de posse de terras às chamadas comunidades de remanescentes quilombolas, entretanto, não significou que essa aquisição acontecesse de forma simples e automática. As proposições constitucionais não previram que esses sujeitos tivessem dinamizado sua estrutura organizacional, em função do próprio sistema social no qual estavam inseridos. A determinação de emissão de títulos apenas às comunidades que estivessem ocupando as terras de antigos quilombos culminou, dessa forma, no primeiro grande entrave para que se fizesse valer os direitos outorgados a esses grupos. Como um dos motivos dessa problemática, podemos citar o fato de, no documento oficial, ocorrer a bricolagem do termo quilombolas, tal como era utilizado no período escravagista. Um princípio básico fora ignorado: o hiato de cem anos entre o fim da escravidão e as determinações constitucionais.

A esse fator, vinculam-se uma série de desdobramentos que deixam de ser essencialmente de cunho lexical. Nesta perspectiva, o antropólogo Jean François Véran argumenta que, na medida em que o texto de lei se referia a uma 
categoria coletiva que já não existia (o quilombo) para dar juridicamente existência a uma categoria coletiva que ainda não existia (a "comunidade remanescente") era preciso, antes de tudo, haver entendimento entre os diversos atores envolvidos no debate sobre a definição do objeto histórico em questão. O que é que se quer dizer, ou ainda, o que se deveria querer dizer com quilombo? (VÉRAN, 1999, p. 297-298)

O questionamento apresentado por Verán chama a atenção para o fato de que as determinações legais postulam a construção de três elementos, a saber: uma categoria coletiva, a dialogia entre as representações do passado e do presente no qual essa categoria faz sentido e, finalmente, o objeto que ela mobiliza e que ela constrói (VÉRAN, 1999, p. 298). A herança de um termo carregado de significação negativa, inerente a um passado histórico, sem a necessária adequação semântica e contextual, resulta em dificuldade da utilização do conceito quilombo, considerando o lugar ocupado pelos quilombolas na atualidade.

Diante da problemática envolvendo o público atendido pelos Artigos Constitucionais 215 e 216 e o Artigo 68 das ADCT, coube ao Estado a criação de alguns arranjos políticos, a fim de que se contornasse a situação. Para que os diretos constitucionais alcançassem um número maior de comunidades negras, duas medidas poderiam ser tomadas: i) substituir os termos em que fica determinado que apenas aos quilombolas ocupantes das terras de antigos quilombos fossem beneficiados e ii) reconstruir a carga semântica do conceito quilombo. E, embora a segunda medida possa parecer, a princípio, a mais complexa, foi a escolhida para "solucionar" a questão.

Desta forma, foi na remodelagem conceitual que se concentrou esforços para que um contingente significativo de famílias - rurais ou urbanas - se tornasse apto ao acionamento dos direitos constitucionais, convertendo-se, após uma série de exigências, em titulares das terras que habitam, sendo essas terras antigos quilombos ou não.

Realizada a nova adequação ao termo quilombo, entretanto, fora imposta, aos quilombolas, a necessidade de se comprovarem, sobretudo culturalmente, como remanescentes. Esse fator tem demandado a participação de atores externos a esses gruposem alta escala, a academia- para que essa comprovação ou leitura do cotidiano dos quilombolas seja feita, a fim de que se detecte características culturais que os liguem a seus ancestrais e os coloquem, de fato, no papel de beneficiários dos direitos atribuídos por lei.

A comprovação da identidade quilombola precisa ser, como assume Barth (2000) pautada em critérios que resistam às atribuições a conceitos e categorias facilmente 
generalizáveis, como comunidades rurais, pequenos produtores, agricultores familiares, dentre outros. De acordo com o autor, apenas os fatores socialmente relevantes podem ser considerados diagnósticos para assinalar os membros de um grupo (BARTH, 2000, p.33).

É preciso chamar a atenção, entretanto, para os riscos eminentes em se buscar os fatores de distinção dessas comunidades, assumindo como base as questões estéticas, o que acaba por incidir no debate sobre raças, há muito repensado nas ciências sociais. A considerar as dinâmicas sociais, que se encontram em constante estado de reconstrução, não é possível esperar que as comunidades de remanescentes quilombolas preservem, no sentido essencializado do termo, suas tradições. Ao contrário, o que percebemos é que, como em qualquer grupo social, algumas comunidades se afastam dessas tradições, em um processo de remodelagem, reconstrução, (re)leitura, reescrita, ou até mesmo rasura do seu passado histórico.

Sob esta perspectiva, a análise e a descrição da forma a partir da qual os quilombolas estão (re)construindo sua identidade étnica, a fim de se enquadrem nas regras estabelecidas para o reconhecimento do grupo como comunidade de remanescentes quilombolas e na aquisição dos direitos fundiários estabelecidos pela Constituição de 1988, passa a ser um dos grandes desafios dos estudiosos concernente à questão.

Muitos têm sido os caminhos pelos quais pesquisadores se enveredam para os estudos sobre a identidade étnica quilombola. Tradicionalmente, o par religião (ritos religiosos) e danças tem sido acionado como uma das formas para se "ligar" quilombolas a um passado de ancestralidade africana. No caso das comunidades em que realizamos a pesquisa de campo que deu origem aos questionamentos aqui apresentados, encontramos, nas práticas e hábitos alimentares, um fértil terreno para se compreender como esses grupos se relacionam com sua ancestralidade, como se localizam socialmente e como demarcam sua identidade.

Partimos do princípio de que seja necessário, como assume Gilroy (2002), pensar nas identidades negras da diáspora como culturalmente híbridas e dinâmicas, dado que se constroem não apenas a partir da memória do trauma original da escravidão e da vivência posterior à violência racial e ao racismo, mas também a partir de uma experiência radical de desenraizamento e constante metamorfose cultural, estrutural à experiência da modernidade.

Essas metamorfoses, sobre as quais diz o autor, estão imbricadas ao caráter relacional da construção das identidades pois, como afirmam Laclau e Mouffe, todas as identidades são relacionais e a condição de existência de uma identidade passaria pela delimitação de um 
outro, que desempenhará o papel de elemento externo constitutivo (apud. MARQUES, 2008).

Sendo assim, na busca pela compreensão das redes de significação que se desenrolam no processo de demarcação identitária étnica a partir do resgate de símbolos de etnicidade, é preciso considerar não somente a densidade sêmica desses símbolos, a partir do ponto de vista do nativo mas, também, o papel dos autores múltiplos que entram no jogo de construção e marcação identitária desses grupos, a saber: acadêmicos, representantes de organizações não governamentais, representantes de organismos do Estado, movimentos sociais, dentre outros.

\section{A COR DO SABOR: alimentação quilombola e questões identitárias}

Como dito anteriormente, os hábitos e as práticas alimentares são elementos que marcam pertença. Ao afirmar que a comida não é apenas uma substância alimentar mas também um modo, um estilo e um jeito de alimentar-se. E o jeito de comer define não só aquilo que é ingerido, como também aquele que ingere, DaMatta (1986, p. 56) nos induz a uma série de questionamentos que se relacionam aos mecanismos dos quais o homem se utiliza para conceder, aos alimentos, o status de comida. Este processo transformador tangencia e aproxima duas dimensões: a física (de manipulação e preparo) e a cultural (de aceitação e identificação social).

É preciso considerar que comer não é um ato solitário, mas sim, um ato social. Embora o mundo contemporâneo tenha reformatado a sistemática alimentar e os restaurantes de fast food comprometam, ou reconfigurem, a construção dos rituais relacionados à alimentação, comemos com quem nos aproximamos culturalmente, com quem construímos um grupo de comensalidade ${ }^{3}$.

As dimensões do quê, quando, como e com quem comer, são responsáveis pela construção de subjetividade, a partir do momento em que por elas perpassam relações não somente entre os quilombolas e os alimentos que comem, mas também entre os próprios quilombolas, entre atores sociais externos às comunidades, e, com percebemos, entre quilombolas e seu passado histórico. E foi a partir dessas relações que pudemos analisar um

\footnotetext{
3 Um grupo de comensalidade é um grupo de pertença. Fazemos parte de uma série de grupos para vivermos em sociedade. Os grupos sociais de pertença ditam normas e condutas àqueles que dele fazem parte, e o grupo de comensalidade nos orienta quanto aos nossos habitus alimentares. Ele nos orienta não somente em termos daquilo que deve ser comido, mas a forma que comemos e na companhia de quem comemos.
}

INTRATEXTOS, Rio de Janeiro, Número Especial 03, pp.54-71, 2012. 
dos matizes da construção da identidade étnica dos quilombolas de Piranga-MG.

Três foram as comunidades nas quais realizamos o trabalho de campo, a partir do qual organizamos a reflexão que ora apresentamos: Santo Antônio de Pinheiros Altos, Bordões e Castro. Dentre as três, Santo Antônio de Pinheiros Altos é a comunidade que possuía, até a data a finalização deste texto, a certidão de autorreconhecimento como comunidade remanescente quilombola. A certidão foi emitida em 2008, ano em que realizamos pesquisa no local. À época, a associação de moradores havia sido organizada com o auxílio de um extensionista rural, quem também tomou a frente em relação aos documentos encaminhados à Fundação Palmares. Pinheiros Altos também é a maior comunidade dentre as três, com cerca de 85 famílias que se dividem, em quase sua totalidade, em dois troncos familiares: os Nicácios e os Acácios.

Quanto a Castro e Bordões, essas são comunidades muito pequenas, com 8 e 12 famílias, respectivamente. As comunidades são geminadas, e ligadas entre si por laços familiares que giram em torno de um morador, o Zé Romão. Todos são irmãos, filhos, sobrinhos, netos, bisnetos, cunhados, ou afilhados de Zé Romão. Embora nos tenha sido relatados os graus de parentesco, não nos foi possível identificar o(s) sobrenomes dos troncos familiares das duas comunidades, já que, até a terceira geração depois de Zé Romão, esses eram determinados de acordo com o Santo padroeiro do dia do nascimento de cada morador, ou seja, em uma família com oito filhos, encontramos oito sobrenomes distintos.

Em 2009, começava a articulação, no sentido de se fundar a associação de moradores em Bordões e Castro. Na verdade, a ideia inicial era a de se fundar uma associação de um complexo de comunidades, o complexo de Bacalhau, ao qual, além de Castro e Bordões, a comunidade de Bacalhau e outras três seriam integradas. As comunidades contavam com o apoio e a articulação de um político local, morador da comunidade de Bacalhau. Até fecharmos este artigo, fomos informados de que a associação havia sido fundada, mas não tivemos maiores informações sobre o pedido da certidão de autorreconhecimento.

Todas as três comunidade possuem plantio de verduras, grãos e frutas -em pequena escala- para a subsistência. Em Pinheiros Altos, grande parte dos homens trabalham em cidades do entorno, permanecendo na comunidade apenas nos finais de semana. As mulheres só saem da comunidade para trabalhar nos períodos de colheita de cana, café e feijão. Chamam essa atividade de panha e trabalham nas fazendas do entorno.

Em Castro e Bordões, ao contrário, os moradores plantam o eucalipto e possuem 
pequenos fornos de carvão, o que faz com que quase toda comunidade permaneça na localidade durante boa parte do tempo. Os programas de Bolsas governamentais- bolsa família, bolsa escola- também fazem parte do orçamento das três comunidades.

À primeira vista, os quilombolas do município de Piranga, salvas as questões estéticas, as quais, já salientamos, serem por demais frágeis para se caracterizar um grupo social, se apresentam como uma comunidade rural comum. Sua vestimenta, sua religião, seus hábitos cotidianos, considerando algumas particularidades, se configuram como os de outras comunidades rurais do entorno.

Ao focarmos nosso olhar para as representações sociais presentes nas práticas diárias que envolvem a alimentação, entretanto, percebemos que, para além das panelas, os quilombolas estabelecem critérios de aceitação dos alimentos e dos utensílios da cozinha, que muito revelam sobre a forma que desejam representar a si mesmos. Foi a partir das práticas e dos hábitos alimentares que conseguimos analisar as múltiplas reconstruções que quilombolas de Piranga fazem de sua memória do passado e as redes de significação que essas possuem no presente.

Isso pode ser percebido, a partir da observação das representações construídas acerca do milho, alimento central da alimentação do município, e também da alimentação dos quilombolas.

A cultura do milho se destaca na região em que se localiza o município de Piranga. Contudo, nas comunidades em que realizamos nosso estudo, além das questões de produtividade, o alimento ocupa lugar singular no imaginário dos quilombolas, determina mudanças de ocupação de espaço social, quando se compara a relação que mantinham com esse alimento o passado.

Esse argumento é defendido a partir de informações que nos foram concedidas através de entrevistas, quando nos foi então revelado que o milho era a moeda de troca pelo trabalho, utilizado pelos fazendeiros da região. É sabido que a abolição não se configurou como um projeto político com propósitos de inserção dos ex-escravos na dinâmica social do país. Esse fator, por sua vez, refletiu diretamente na forma a partir da qual esses atores passaram a conviver com seus antigos donos, os quais passaram de proprietários a patrões, já que poucas (ou quase nenhuma) eram as oportunidades que os negos tiveram, após ganharem sua liberdade. Sendo assim, continuavam prestando serviços nas fazendas de seus antigos senhores os quais, em grande maioria, faziam o pagamento em troca de alimentos. 
O milho entra nesse contexto como um alimento de difícil acesso. Como nos foi relatado, ele utilizado como moeda de pagamento apenas quando havia excesso ma produção, uma saca desse produto era muito valorizada, equivalia a todo um dia de trabalho ${ }^{4}$. Na atualidade, entretanto, muitas são as diferenças percebidas, no que se refere ao contexto de acessibilidade do milho nas comunidades quilombolas de Piranga. Ao contrário do que acontecia no pós-abolição, ou seja, no final do século XIX, hoje os quilombolas plantam o milho em suas próprias hortas, armazenam o alimento em seus próprios paióis, cozinham nas cozinhas de casas que são suas e servem a família e as visitas, longe das lembranças dos cativeiros e das punições da privações da escravidão.

Essa mudança na relação com esse alimento emblemático revelou-se singular na configuração do espaço social que os quilombolas ocupam na atualidade, o que foi marcado pela fala de alguns moradores que chamaram atenção para o fato de "hoje poderem comer milho na hora que desejam". O acesso ao alimento se mostrou como um evento digno de orgulho para esses grupos, na medida em que, como disseram, representa o fato de não mais necessitarem de trabalhar dia e noite para que possam comer milho.

O milho está presente, tanto nos pratos do cotidiano, através do angu, que é servido no almoço e na merenda ${ }^{5}$. Nos pratos que eram tradicionalmente preparados nas fazendas, e hoje são preparados pelos quilombolas, ele está presente, principalmente, no cuscuz de rapadura ${ }^{6} \mathrm{e}$ na broa. Às visitas, também é reservado um prato à base de milho, o mingau gelado de milho verde. Raramente os quilombolas oferecerão angu a um visitante, a alguém que não consideram íntimos do grupo. Só nos foi ofertada uma refeição com angu depois que passamos a frequentar a cozinha, outro sinal e aceitação no grupo. Podemos inferir, desta forma, que o milho é um elemento na cultura dos quilombolas de Piranga que simboliza mudança de ocupação de espaços marcados econômica e etnicamente.

O milho, a possibilidade de acesso a ele, o processo de transformação no alimento em comida, é a metáfora da libertação efetiva. Ele representa a liberdade social e econômica desses grupos. Comer milho hoje significa, para os quilombolas, poder ocupar o espaço, antes

\footnotetext{
${ }^{4}$ Em outro trabalho, Santos (2009) discorremos detalhadamente sobre as dificuldades enfrentadas pelos escravos recém libertos, que passaram à categoria de trabalhadores mas continuaram, na prática, dependentes de seus antigos senhores, escravos de uma abolição que não fora um projeto de inserção social.

${ }^{5}$ A categoria merenda se refere ao café da manhã e aos lanches feitos no final da tarde.

${ }^{6} \mathrm{O}$ cuscuz é o doce mais tradicional dos quilombos. A mistura de farinha de milho fina com a rapadura se transforma em uma espécie de doce em barra com sabor singular, após um processo de cozimento diferenciado, proporcionado pelo formato da panela especial, a cuscuzeira de pedra-sabão.
} 
preenchido pelos fazendeiros escravistas, donos da liberdade de seus pais e avós. Além disso, a partir das escolhas das receitas à base desse alimento, percebemos que quilombolas determinam quem são os de dentro e quem são os de fora do quilombo.

Associado ao milho, está o moinho de beneficiamento. Juntamente com o milho, o moinho acompanha a trajetória da ascensão desses sujeitos. O instrumento responsável pelo processo de transformação do alimento em comida também pode ser inserido no campo da leitura de signos que representam a independência dos quilombolas.

Da mesma forma que o milho não era alimento frequente nas panelas dos ex-escravos, os antepassados dos quilombolas de Piranga, o moinho também passa a fazer parte da cultura desses grupos anos após a abolição. Infelizmente, não nos foi possível, através de relatos e entrevistas, precisar a data da construção desses instrumentos que são fundamentais na lógica organizacional das comunidades.

Há uma diferença na maneira a partir da qual as comunidades se relacionam com o uso do moinho. Em Pinheiros Altos, o moinho não se localiza dentro da propriedade de um morador. Ele é um bem comum, cuidado por uma guardiã, que é a pessoa responsável pelo recebimento dos grãos e cronometragem da moagem. Desta forma, a comunidade se organiza em termos de dias da semana e quantidade de milho moída para cada morador. Em Castro não há moinhos; a comunidade se utiliza dos dois existentes em Bordões. E, embora os moinhos de Bordões também sejam utilizados por todos os moradores das duas comunidades, eles se localizam dentro de propriedades; possuem donos. O responsável pelo recolhimento e cronometragem dos grãos é uma liderança na comunidade, um jovem indicado para ser o presidente da associação dos moradores, quem também foi nosso guia local durante os três meses de trabalho de campo. A entrada nos moinhos das comunidades está, desta forma, associada à autorização dada pela guardiã ou pelas donas dos mesmos e, no caso de não moradores, ocorre sempre na companhia de um deles.

Podemos dizer que os quilombolas de Piranga estão ligados pelos laços de parentesco, e pela utilização do moinho. Os moinhos, o acesso a eles, demarca os de dentro e os de fora das comunidades quilombolas.

Dentro desta lógica, a relação que estabelecem com o milho é, a todo momento, interpelada pela presença do moinho. Da mesma forma que não precisam trabalhar para alguém para ter sua saca de milho, não precisam depender de ninguém para a produção de sua farinha. Se o milho simboliza a independência no sistema produção, o moinho a representa no 
processo transformador. Ou seja, podemos perceber que não somente o milho, mas outros elementos simbólicos da prática alimentar quilombolas são instrumentos que traduzem as relações, as mudanças e as reconstruções ocorridas em relação ao passado desses grupos.
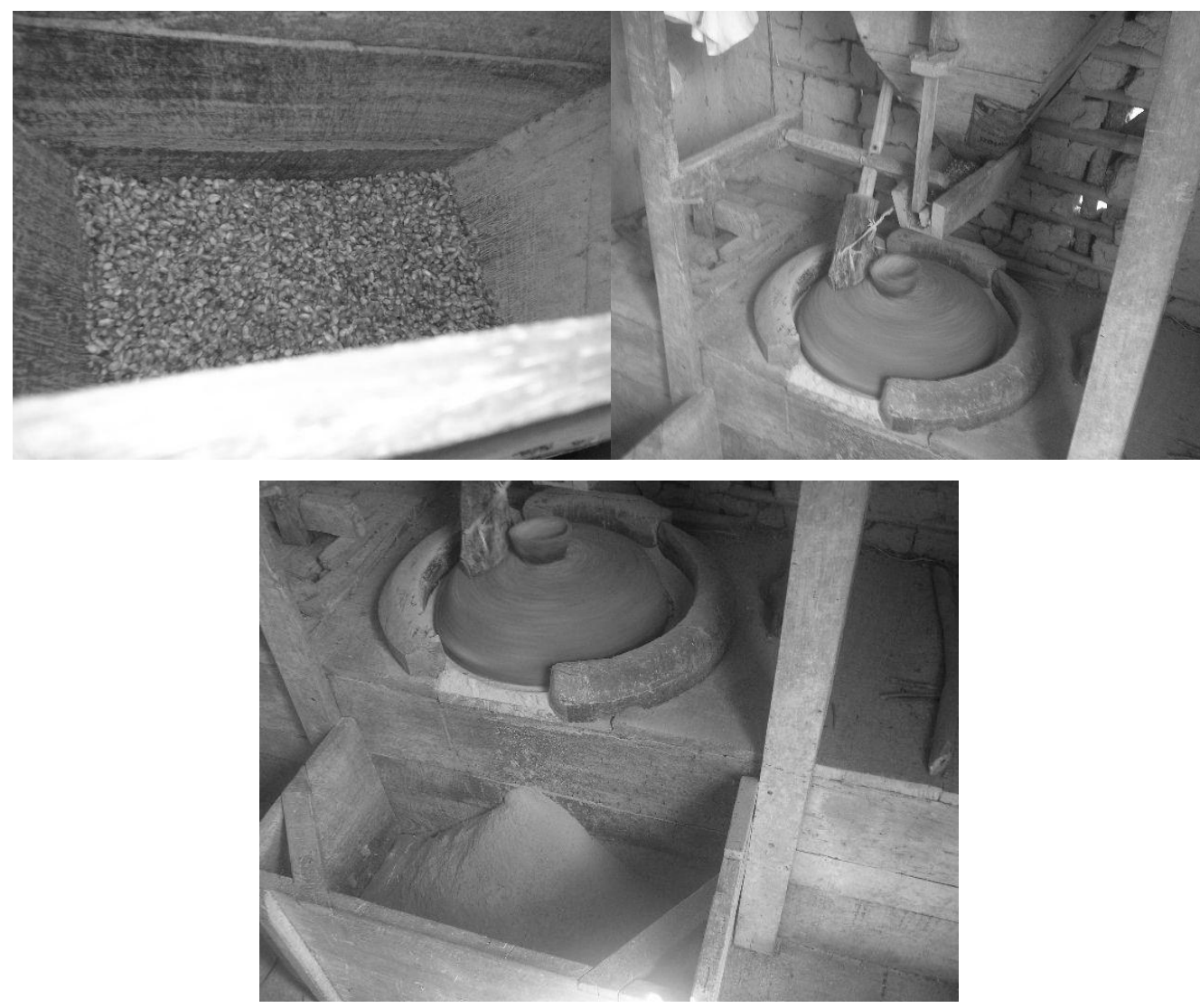

Figura 1: Beneficiamento do milho realizado nos moinhos.

(Foto: Alexandra Santos)

Outro signo essencial para a tradução da identidade étnica quilombola de Piranga são os fogões a lenha. $O$ fogão a lenha tem uma série de implicações na lógica social dos grupos em que realizamos a pesquisa. Uma delas é a função de demarcar a localização da cozinha enquanto cômodo da casa. Independente de quaisquer outros objetos presentes no cômodo, chama-se de cozinha o local onde o fogão é construído. $\mathrm{O}$ fogão a gás não tem o mesmo status e pode se encontrar na área ou em algum um cômodo, junto à geladeira. O fogão a lenha é a centralidade da cozinha, que pode ser também o espaço de lavar roupas, guardar mantimentos ou de prosear.

Percebemos que os fogões a lenha de Piranga ocupam um lugar especial no imaginário que a comunidade cria de si mesma. Tal afirmativa se sustenta na base de que os moradores 
os exibem como o que de mais valioso têm em suas casas. Pousam para fotos na frente do fogão e, quando apresentam suas casas é para eles que chamam a atenção. Exibem o utensílio, cuidadosamente limpo e guarnecido de lenha. Não foi possível confirmar a data precisa do evento mas, chamou-nos a atenção o movimento que tem se instaurado nos quilombos: o revestimento dos fogões a lenha com cerâmica, na quase totalidade dos casos, branca. Podemos afirmar ser um movimento recente, dado que o fogãozeiro oficial, ou seja, a pessoa responsável pelo revestimento de grande parte dos fogões, é um senhor de 40 anos. Pedreiro nas cidades de Ouro Preto e Mariana, decidiu utilizar o material de seu serviço para recobrir o antigo fogão a lenha de barro que possuía em casa. Recobrir o barro com a cerâmica passou a ser um símbolo de modernidade, de poder econômico, de identificação.

Em quase todas das casas, não se vê mais fogões de barro. Aos poucos, todos eles têm sido artisticamente revestidos. Esse desejo e forma de se revestir o fogão marcam os quilombolas dentro de uma nova dinâmica social já que: i) os fogões ainda em barro são justificados pela falta de oportunidade financeira para a execução do revestimento; ii) os fogões já revestidos há mais tempo, ou seja, os que não seguem o movimento atual, são cobertos com "tijolinhos", não com cerâmica. Esse tipo de revestimento marca a diferença hereditária do morador, o seja, nas casas em que encontramos o fogão revestido com o tijolinho, os moradores faziam questão de frisar que a reforma era antiga, não fazia parte do processo de revestimento atual, sempre tiveram condições financeiras boas, por isso o revestimento de seus fogões havia sido realizado há muito tempo. Esses fogões foram encontrados nas casas de moradores com vínculos familiares dos antigos fazendeiros, não com os ex-escravos. Percebemos, assim, que o revestimento do fogão a lenha, simboliza uma nova ocupação de espaço econômico, mas que, ainda assim, marca particularidades dentro do grupo.

O material utilizado para o revestimento dos fogões, desta forma, além de marcar o tempo, marca o tempo, as relações com a ancestralidade, o espaço social ocupado hoje e no passado. O revestimento do fogão a lenha marca a comunidade também em termos econômicos. Consideram importante dizer quem foi o primeiro a ter condições de fazê-lo. Uma das moradoras afirmou ser o seu fogão, o primeiro a ter sido revestido com a cerâmica. Seu marido é "fogãozeiro" famoso da localidade. Ele faz questão de fazer todos os fogões milimetricamente iguais, a fim de que sua "obra de arte" seja reconhecida. A moradora não soube precisar, mas afirmou que seu fogão não tem mais de dez anos, o que nos leva a 
assumir que o movimento de remodelagem identitária - verificado através da reforma dos fogões a lenha- tem se fortificado na última década.

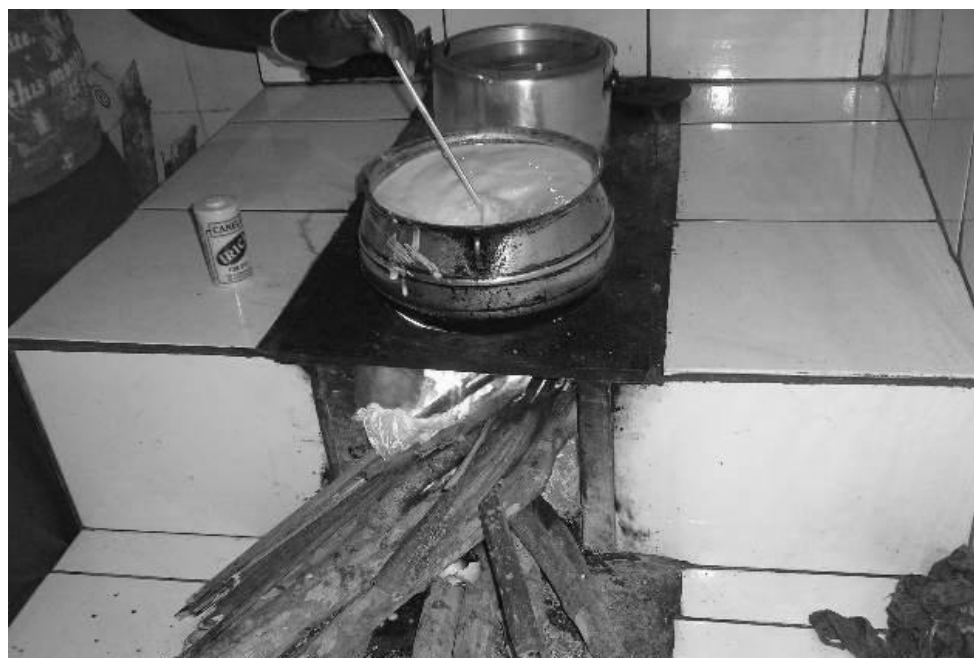

Figura 2 : Fogão a lenha. Santo Antônio de Pinheiros Altos.

(Foto: Alexandra Santos)

Além do fogão a lenha, encontramos uma série de elos e marcas identitárias nas relações que quilombolas estabelecem com o pilão e com a cuscuzeira, (SANTOS, 2009). Todos esses signos nos informam que os quilombolas de Piranga, a partir de suas práticas e hábitos alimentares, (re)constroem sua identidade étnica e demarcam sua identidade e que nas decisões quanto ao que comer e com quem comer revelam como os se aproximam e se afastam do outro, construindo sua subjetividade.

\section{CONSIDERAÇÕES FINAIS}

Com este artigo, procuramos pensar na possibilidade de estudar o processo de construção e acionamento da identidade étnica quilombola, a partir de sua prática alimentar, considerando que as representações que emergem das relações que os sujeitos estabelecem com o alimento, quanto às escolhas daquilo que comem, a forma que comem e na companhia de quem comem, atuam como importantes dados culturais. A partir desses dados, podemos compreender como esses grupos se relacionam com seu entorno, consigo mesmos, com seu passado e com os múltiplos atores sociais integrados à comunidade, ou seja, acadêmicos que, como nós, pesquisam sobre a questão quilombola no país, profissionais de extensão rural e políticos, que passaram a frequentar a comunidade após a entrega da certidão de 
autorreconhecimento, dentre outros.

Percebemos que as possibilidades de análise oriundas da observação das escolhas que envolvem a prática e os hábitos alimentares nos conduzem a uma série de variáveis sobre os espaços sociais ocupados pelo comedor quem se representa a partir daquilo de come, da forma como come e na companhia de quem come.

Ainda, nossa pesquisa demonstrou que não somente os alimentos, mas vários elementos que compõem a cozinha, enquanto local de socialização e integração social, contribuem para a construção identitária dos quilombolas de Piranga. A partir da análise das relações que se estabelecem pelas bordas das panelas, torna-se possível pensar nas representações sociais que esses grupos criam de si, das relações que estabelecem com seu passado histórico e com o momento presente. Além disso, embora não tenha sido um dos elementos de análise de trabalho, é possível, a partir da análise das práticas alimentares, compreender uma série de conflitos existentes entre esse grupos, conflitos esses que perpassam tanto pela forma a partir da qual se relacionam com seu passado, quanto pelas perspectivas que constroem em torno desse momento de construção de uma identidade, até então não acionada por esses grupos: a identidade quilombola.

Desta forma, com este trabalho, tentamos trazer algumas contribuições para este cenário cheio de possibilidades a serem descobertas, ou seja, o da compreensão das múltiplas formas de operacionalização da construção de uma identidade étnica de quilombolas contemporâneos. Muitos são os caminhos que se pode seguir para a tradução da cultura desses grupos, apresentamos, aqui, uma saborosa e intrigante estrada a ser percorrida.

\section{Referências Bibliográficas:}

BARTH, Fredrik. O guru, o iniciador e outras variações antropológicas. LASK, Tomke (org) Rio de Janeiro: Contra Capa Livraria, 2000.

BRILlAT-SAVARIN, Jean-Anthelme. A Fisiologia do Gosto. São Paulo: Companhia das Letras, 1995 
DAMATTA, Roberto. O que faz o Brasil, Brasil?. Rio de Janeiro: Rocco, 1986

Gilroy, Paul. O Atlântico Negro - Modernidade e Dupla Consciência. Rio de Janeiro, Editora 34/UCAM — Centro de Estudos Afro-Asiáticos, 2001

FISCHLER, Claude. L'homnivore. Paris: Poche Odile Jacob, 2001

MILlÁn, Amado. Malo Para Comer, Bueno Para Pensar: crisis en la cadena socioalimentaria. In: ARNAIZ, Mabel Gracia (coord.). Somos lo que comemos: estudios de alimentación y cultura en España. Barcelona: Ariel, 2002.

MINTZ, Sidney W. Comida e Antropologia: uma breve revisão. Revista Brasileira de Ciências Sociais. Vol 16, no 47, p. 31-41, 2001.

SANTOS, Alexandra. Entre a colher e a enxada: interfaces entre a alimentação e a cultura quilombola. 170f. Dissertação (Mestrado em Extensão Rural) Departamento de Economia Rural, Universidade Federal de Viçosa, Viçosa, Minas Gerais, 2009

VÉRAN, Jean-François, Brésil : les découvertes du quilombo. La construction hétérogène d'une question nationale, Problèmes d'Amérique Latine n³2, janvier-mars, pp.53-72, 1999 